\title{
Analysis of close conjunctions between dayside polar cap airglow patches and flow channels by all-sky imager and DMSP
}

\author{
Boyi Wang ${ }^{1 *}$, Yukitoshi Nishimura' ${ }^{1}$ Larry R. Lyons ${ }^{1}$, Ying Zou ${ }^{1}$, Herbert C. Carlson ${ }^{2}$, Harald U. Frey ${ }^{3}$ \\ and Stephen B. Mende ${ }^{3}$
}

\begin{abstract}
Recent imager and radar observations in the nightside polar cap have shown evidence that polar cap patches are associated with localized flow channels. To understand how flow channels propagate from the dayside auroral oval into the polar cap, we use an all-sky imager in Antarctica and DMSP (F13, F15, F16, F17 and F18) to determine properties of density and flows associated with dayside polar cap patches. We identified 50 conjunction events during the southern winter seasons of 2007-2011. In a majority (45) of events, longitudinally narrow flow enhancements directed anti-sunward are found to be collocated with the patches, have velocities (up to a few $\mathrm{km} / \mathrm{s}$ ) substantially larger than the large-scale background flows $(\sim 500 \mathrm{~m} / \mathrm{s})$ and have widths comparable to patch widths ( 400 km). While the patches start with poleward moving auroral forms (PMAFs) as expected, many PMAFs propagate azimuthally away from the noon over a few hours of MLT, resulting in formation of polar cap patches quite far away from the noon, as early as $\sim 6$ MLT. The MLT separation from the noon is found to be proportional to the IMF |By|. Fast polar cap flows of $>\sim 1500 \mathrm{~m} / \mathrm{s}$ are predominantly seen during large IMF |By| and small |Bz|. The presence of fast, anti-sunward flow channels associated with the polar cap patches suggests that the flow channels form in the dayside auroral oval through transient reconnection and can be the source of flow channels propagating into the polar cap.
\end{abstract}

Keywords: Dayside polar cap, Airglow patches, Flow channels, AGO ASI, DMSP satellites, IMF

\section{Introduction}

Although the polar cap is optically much darker than the auroral oval in general, sensitive all-sky imaging in $630.0 \mathrm{~nm}$ wavelength shows polar cap patches, which are airglow emissions that result from recombination between electrons and molecular oxygen ions that have higher density than in surrounding regions (e.g., Weber and Buchau 1981). The patches of high-density plasma are $\sim 100$ to $1000 \mathrm{~km}$ in size, and the islands of plasma originate from solar-EUV-produced ionospheric plasma that enters the polar cap through the cusp dayside auroral region (Knudsen 1974; Foster 1984; Carlson 2012). Their slow ( hours) F region recombination allows their

\footnotetext{
*Correspondence: bywang@ucla.edu

1 Department of Atmospheric and Oceanic Sciences, University

of California, Los Angeles, Los Angeles, CA, USA

Full list of author information is available at the end of the article
}

motion to be tracked over long distances, and their trajectories over the polar cap have been believed to follow large-scale two-cell convection during southward interplanetary magnetic field (IMF) (Hosokawa et al. 2010; Oksavik et al. 2010; Carlson 2012). Patches become particularly large during geomagnetic storms (called tongue of ionization) and form a channel of enhanced density from the dayside and nightside auroral oval across the polar cap (Foster et al. 2005). The IMF By also controls dawn-dusk motion of patches (Moen et al. 2008a; Hosokawa et al. 2009). Convection within the polar cap is often assumed to consist of relatively uniform anti-sunward flow with a typical speed of several hundreds of $\mathrm{m} / \mathrm{s}$ (e.g., MacDougall and Jayachandran 2001).

In contrast, around the dayside cusp region, plasma flow observations have shown dynamic mesoscale (of the order of $100 \mathrm{~km}$ ) structures that may be involved in the creation of localized patch structures (Pinnock et al. 1993; 
Oksavik et al. 2004, 2005; Carlson et al. 2006; Rinne et al. 2007; Moen et al. 2008b; Zhang et al. 2013a). Recently, Goodwin et al. (2015) used SWARM data to document the intake of solar-EUV plasma through fast flow channels. Those fast flows are also associated with poleward moving auroral forms (PMAFs), which are considered to be an ionospheric signature of localized dayside magnetic reconnection and flux transfer events (FTEs) (Moen et al. 1995; Provan et al. 1998, 1999; Provan and Yoeman 1999; McWilliams et al. 2000; Milan et al. 2000; Sandholt and Farrugia 2003; Lockwood et al. 2005; Carlson et al. 2006; Zhang et al. 2011, 2013b). PMAFs initiate near the poleward boundary of the dayside auroral oval and then propagate poleward before fading away (Lorentzen et al. 2010). The mean lifetime of PMAFs is $\sim 10 \mathrm{~min}$, anti-sunward velocity is $\sim 1 \mathrm{~km} / \mathrm{s}$, and latitudinal motion is $\sim 5^{\circ}$ (Drury et al. 2003 and references therein).

Decaying PMAFs have been found to be associated with high-density plasma that continues propagating into the polar cap as airglow patches (Carlson et al. 2004, 2006; Lorentzen et al. 2010). This connection suggests that mesoscale fast flows around the cusp may extend into the polar cap in association with patches and that they may extend deep into the polar cap. However, since observations of PMAFs and dayside patches are often limited to the dayside cusp region, these possibilities have rarely been examined.

Some polar cap patches have been shown to propagate deep into the polar cap and reach the nightside polar cap (Oksavik et al. 2010), and they can even exit the polar cap through magnetic reconnection and enter the nightside auroral oval (Zhang et al. 2013b). Moen et al. (2015) also addressed the IMF By effects of intake and exit of polar cap patches. Polar cap patches are also observed in the nightside polar cap, and they have been seen to propagate to the nightside auroral oval and connect to auroral poleward boundary intensifications (PBIs) and streamers (Lorentzen et al. 2004; Moen et al. 2007; Nishimura et al. 2013). Although those studies did not investigate whether the patches in the nightside polar cap are associated with mesoscale flows, recent radar observations have shown the existence of mesoscale fast flows deep within the nightside polar cap. Those fast flows propagate toward the nightside auroral oval and influence nightside auroral intensifications (Nishimura et al. 2010; Lyons et al. 2011; Zou et al. 2014). The similarities between mesoscale flow channels in the dayside cusp and within the nightside polar cap, as well as the patch propagation from the dayside to nightside polar cap, suggest that mesoscale fast flows in the dayside oval propagate deep into the polar cap (Wilder et al. 2012 and references therein). In fact, a recent case study using airglow patch and radar flow observations by Nishimura et al. (2014) showed a nearly continuous sequence from a dayside PMAF to nightside PBIs, across the polar cap, associated with mesoscale fast flows.

Patches have also been found in association with rapid flow channels, which are typically $\sim 2 \mathrm{~km} / \mathrm{s}$, at the beginning of their formation on the dayside (Carlson 2012). Zhang et al. (2013a, b) also suggested that flow bursts lead to the formation of patches. However, flow observations associated with polar cap patch propagation are limited in the dayside polar cap, so that there has not been a systematic study of whether or not dayside polar cap patches are associated with these mesoscale flow channels propagating deep into the polar cap after patch formation. To investigate the relation between airglow patches and mesoscale flows inside the polar cap, we use coordinated observations by one of the Automatic Geophysical Observatories (AGO) all-sky imagers (ASIs) in Antarctica, and the Defense Meteorological Satellite Program (DMSP) satellites. While airglow patch emissions primarily occur below $300 \mathrm{~km}$ altitude, density enhancements associated with airglow patches have been known to extend to much higher altitudes along magnetic field lines. For example, Carlson et al. (2006) used imaging and EISCAT and showed that density enhancements associated with patches extend to $600 \mathrm{~km}$ altitude or higher. Hosokawa et al. (2009) used DMSP and imager data, as we do in this study, and showed that density enhancements at DMSP altitude correspond to airglow patches.

ASI observations can trace 2-D motions of airglow patches over long distances. Although dayside imaging in the dayside polar cap is very limited by sunlight and clouds, the AGO imagers have multi-years of records in low cloudiness ( $10 \%)$. While radar backscatter echo regions are generally not sufficiently large to investigate flow structures around polar cap patches (including the events studied here), low-altitude satellite observations can provide both density and velocity over a wider region along their trajectories, and their conjunctions with imagers occur routinely, allowing us to perform a statistical study of airglow patches and related flow structures in the dayside polar cap. We note that, although low-altitude satellite observations have been used to study PMAFs (e.g., Lockwood et al. 2001; Sandholt et al. 2004), studies using conjunctions with dayside polar cap patches (Hosokawa et al. 2010) have been rare.

Using these coordinated observations, we systematically examine whether dayside polar cap patches are associated with localized polar cap flow enhancements or are immersed in large-scale convection. Furthermore, we also investigate dependencies of density and flow structures on their MLT location and on the IMF. 


\section{Data set and event selection}

The imager data we utilize to identify patches are provided by one of the monochromatic ASIs of the AGO network in Antarctica (Mende et al. 1999). The AGO ASIs acquire images in two different wavelengths (630.0 and $427.8 \mathrm{~nm}$ ). Among the AGO stations, we use the AP1 $\left(83.86^{\circ} \mathrm{S}, 129.61^{\circ} \mathrm{E}\right.$ in geographic; $80.14^{\circ} \mathrm{S}, 16.87^{\circ} \mathrm{E}$ in magnetic) station, which has the longest record and stays in the polar cap for almost all times on the dayside. This ASI records imager data every minute with two different exposure times. We used the long-exposure mode $(8 \mathrm{~s})$ for maximizing the chance of detecting faint airglow patches. Data at $630.0 \mathrm{~nm}$ wavelength are mapped to $230 \mathrm{~km}$ altitude and are used to observe both auroral and airglow emissions. Since emissions at $427.8 \mathrm{~nm}$ are only sensitive to energetic electron precipitation, these two wavelengths can be used to distinguish auroral and airglow emissions. Images are digitized and scaled between 0 and 255 in arbitrary intensity units. Poleward boundaries of the auroral oval are deduced from the $427.8 \mathrm{~nm}$ and are checked using the electron precipitation data from the DMSP conjunctions.

We assumed that the altitude of images observed by red $(630.0 \mathrm{~nm})$ emissions is $230 \mathrm{~km}$ since the most significant red emissions occur at this altitude. Similarly, we map blue $(427.8 \mathrm{~nm})$ emission snapshots to $110 \mathrm{~km}$. These are typical mapping altitudes at these wavelengths (Gulledge et al. 1968; Axelsson et al. 2014; Sakai et al. 2014). However, there are some errors associated with this mapping. To estimate the errors, we use intensity profiles for airglow red emission presented by Sakai et al. (2014), which showed that the airglow emission of polar cap patches is peaked at $\sim 280 \mathrm{~km}$ altitude during disturbed time. The errors from the $230 \mathrm{~km}$ altitude mapping can be estimated as:

$W_{280}-W_{230}=W_{230} \times(280-230) / 230 \approx 0.21 \times W_{230}$

where $W_{230}$ and $W_{280}$ denote the horizontal lengths at different altitudes.

Thus, the uncertainty of $W_{230}$ is about $20 \%$. This is not negligibly small but indicates that $W_{230}$ gives a reasonable estimate of a horizontal length. For most of the airglow patches in this study ( $300 \mathrm{~km}$ width), the uncertainties are approximately a few tens of kilometers.

We also use available DMSP satellites (F13, F15, F16, F17 and F18) measurements of plasma density, flow and particle precipitation using the ion scintillation monitor (SSIES) and precipitating electron and ion spectrometer (SSJ/4). DMSP satellites have 101-min, sun-synchronous near-polar orbits at an altitude of $830 \mathrm{~km}$ above the surface of the Earth. Compared to radars, whose echo coverage is generally sparse, low-altitude satellite observations can provide density, velocity and precipitation across the polar cap along their track. The precipitating particle data are used to validate the optical auroral poleward boundary location along the satellite tracks. The DMSP satellites enter the field of view (FOV) of AP1 several times per day, providing a high chance of conjunctions with airglow patches. It is noted that, because of the trajectories of satellites, most conjunctions with the imager occurred $\sim 11: 00$ to 18:00 UT, which corresponds to the dawn to post-noon regions ( 07:00 to 14:00 MLT).

We have surveyed the southern winter months (from April to September) during 2007-2011. We focused on dark and clear sky conditions and large patches that lasted for at least $10 \mathrm{~min}$ inside the FOV of ASI images during $\sim 1030$ to 2130 UT ( 0600 to 1800 MLT) when the ASI FOV covers a broad area over the dayside polar cap. Airglow patches were identified in $630.0 \mathrm{~nm}$ as $>\sim 15$ intensity units above background (surrounding intensity) with no substantial 427.8-nm emissions. From a comparison to DMSP density data, this intensity threshold corresponds roughly to a factor of 2 increase in density at the DMSP altitude. To identify polar cap flow structures around airglow patches, we required that the satellites fly over the patches identified in the ASI data within $\pm 6 \mathrm{~h}$ MLT from magnetic noon. Since we only use the crosstrack velocity component, we required the angle between the track of the airglow patch and the track of the corresponding DMSP satellite to be between $40^{\circ}$ and $130^{\circ}$ for measuring the dominant velocity component. Based on these criteria, we obtained 50 cases for analysis during the southern winter seasons of 2007-2011, the conjunctions being primarily in the pre-noon sector due to the MLT of the satellite orbit. The list of events is given in Additional file 1.

\section{Case study}

By searching all cases from 2007 to 2011 based on AGO ASI images and DMSP satellites, we found that most airglow patches are associated with mesoscale (few hundred $\mathrm{km}$ width) fast anti-sunward flows. We first present two cases showing a dynamic dayside polar cap with airglow patches and corresponding flow structures in the prenoon and near dawn sectors. For comparison, an event during a quiet time without polar cap patches is also shown as a third case.

\section{First case study: June 10, 2008}

The first two rows of Fig. 1 present a case on June 10, 2008. The auroral oval lies at $\sim-75^{\circ}$ to $80^{\circ}$ magnetic latitude (MLAT). While the 630.0-nm-wavelength emission detects both aurora and airglow patches, the poleward boundary of the auroral oval can be identified as the poleward-most 427.8-nm emission as visually traced by magenta lines in the 427.8-nm snapshots (the left half of 
the 427.8-nm images are contaminated by artificial light). Those lines are also drawn in the 630.0-nm snapshots at the corresponding times. While much of the $630.0-\mathrm{nm}$ emission is equatorward of the magenta lines, meaning auroral emission, the top right portion of the 630.0-nm emission within the 427.8-nm image FOV can be seen to extend $3^{\circ}-4^{\circ}$ poleward, indicating that this emission is polar cap patches. DMSP 15 crossed this region as shown by the blue arrow.

The optical emissions were not steady but included anti-sunward propagation. This optical sequence started with a new auroral brightening within the imager FOV at $\sim 8$ MLT and $\sim 12: 54$ UT (Fig. 1Aa, Af, white dashed circle). This can be identified as a PMAF because both wavelengths detected the formation and slight poleward propagation of this structure within the auroral oval. This PMAF also propagated azimuthally away from noon (Fig. $1 \mathrm{Ab}, \mathrm{Ag}$ ) and was observed in $427.8 \mathrm{~nm}$ clearly until it faded after 13:00 UT. In contrast, the 630.0-nm images showed this emission to propagate further poleward and azimuthally. When DMSP 15 entered AP1's FOV, no discernible 427.8-nm emission was detected over a large portion of this structure as seen in $630.0 \mathrm{~nm}$ (Fig. 1Ad, Ai). Thus, this optical sequence can be interpreted as the PMAF evolving to a polar cap airglow patch that propagated mainly along the auroral poleward boundary without detaching from it. This 630.0-nm luminosity is not due to low-energy precipitation but high-density plasma, because, as shown by the DMSP data in Fig. 2c, e, a distinct plasma density enhancement was seen without substantial electron precipitation.

The left column of Fig. 2 displays, from top to bottom, the optical luminosity along the satellite's track (both the original and after background subtraction), and the density, velocity, electron energy flux and ion energy flux measured by DMSP 15 around the time of the conjunction with AP1 for the June 10, 2008 case. The luminosity of the ASI images along the track of DMSP 15 has a large background that varies along the track (Fig. 2a). Thus, to focus on the propagating PMAFs and airglow patches, we subtracted a background defined as the average luminosity at each pixel during the 2-h period prior to the satellite measurement at that pixel location (dashed line). Although background optical emission is large in this case, the background-subtracted data in Fig. $2 b$ shows two enhanced luminosity regions, although the second peak is not clearly seen in Fig. 1Ae snapshot. The poleward boundary of electron precipitation in Fig. 2e is seen at 1300:50 UT based on a sharp drop of electron fluxes at several hundred $\mathrm{eV}$, and this latitude $\left(\sim-78^{\circ}\right)$ is consistent with the 427.8-nm boundary location shown in Fig. 1A. The luminosity enhancement at $\sim 1300: 50$ to 1302:10 UT is not associated with significant electron precipitation but coincides with an electron density enhancement in Fig. 2c. This indicates that the red emission intensity enhancement within the polar cap region just poleward of the auroral oval corresponds to airglow patches.

Interestingly, the horizontal cross-track plasma velocity (Fig. 2d, positive sunward) showed remarkable antisunward flow bursts localized around the peaks of the enhanced density ( $\sim 600 \mathrm{~km}$ width along the track). Since DMSP 15 passed over the optical airglow patch at $\sim 1300: 50$ to 1302:10 UT almost perpendicular to the azimuthal patch propagation direction, measured velocities are approximately along the propagation direction. The maximum anti-sunward velocity reached $\sim 2800 \mathrm{~m} / \mathrm{s}$, and this is almost an order of magnitude larger than the large-scale background flow seen deep in the polar cap later in this time interval $(\sim 300 \mathrm{~m} / \mathrm{s})$. At the same time, fast sunward flows $(>1000 \mathrm{~m} / \mathrm{s})$ are also identified at 1300:50, 1301:47 and 1302:55 UT. Although these sunward flows are much more localized than anti-sunward fast flows, they and the large anti-sunward flows around indicate the large flow shears in this flow pattern. The density-flow channel relation is also seen within two more polar cap density enhancements with smaller magnitudes (1302:30 and 1303:00 UT), both of which were associated with anti-sunward flow bursts. Although those smaller density enhancements were not resolved by the ASI possibly due to their weaker airglow emissions and the limited imager spatial resolution, the optical sequence of the azimuthal motion of the detectable airglow patch suggests that the enhanced density and flow bursts are spatial structures moving anti-sunward rather than temporal variations.

\section{Second case: April 15, 2008}

Similar to the previous case, much of the $630.0-\mathrm{nm}$ emission of the April 15, 2008 (Fig. 1B) case is found at $\sim-75^{\circ}$ to $80^{\circ}$ MLAT. Here, because the contamination in the eastern region of 427.8-nm emission is too strong compared to the western region, in which PMAFs and airglow patches are active, we subtracted the quiet background for each snapshot in Fig. $1 \mathrm{Bf}-\mathrm{Bj}$ to make the western region of 427.8-nm emission clearer. Similarly, as Fig. $1 \mathrm{Af}-\mathrm{Aj}$, the magenta lines in Fig. $1 \mathrm{Bf}-\mathrm{Bj}$ also indicate dayside auroral oval boundary based on the 427.8$\mathrm{nm}$ emissions. Since no 427.8-nm emission was found above these lines, the $630.0-\mathrm{nm}$ emission poleward of this can be identified as airglow emission. There are more than one auroral/airglow structures moving azimuthally and poleward. Two of those are marked by the white and green dashed circles. In both red (Fig. $1 \mathrm{Ba}$ ) and blue (Fig. 1Bf) emission snapshots, a brightening structure with poleward and azimuthal motion, highlighted 


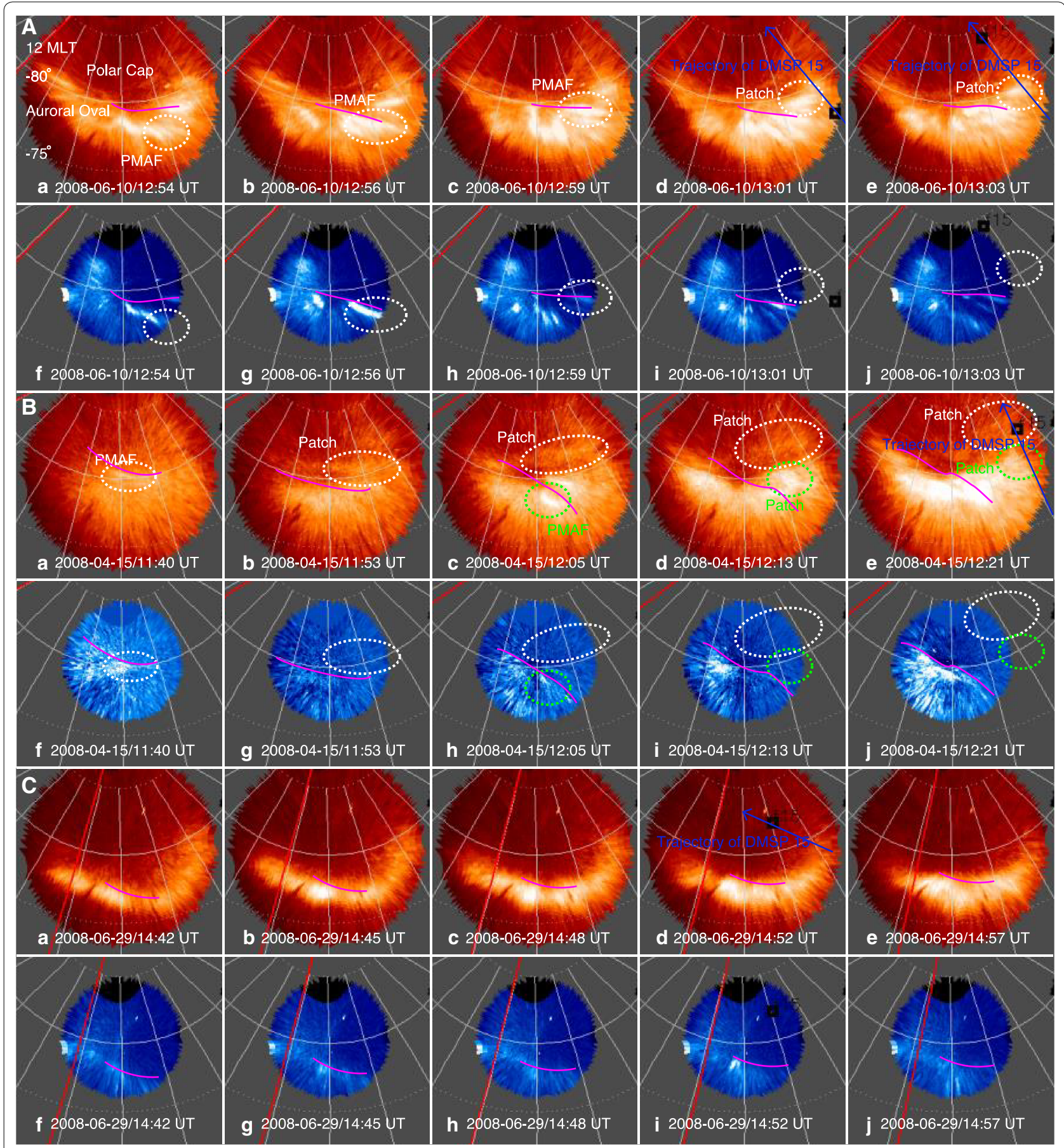

Fig. 1 Snapshots of ASI data at AP1 on (Aa-Aj) June 10, 2008, (Ba-Bj) April 15, 2008, and (Ca-Cj) June 29, 2008. Snapshots in red and blue are in 630.0 and $427.8 \mathrm{~nm}$, respectively. Magenta curves indicate the poleward auroral oval boundary. The dashed circles highlight the PMAFs and airglow patches that we focus on and the black squares show the footprints of DMSP satellites, of which trajectories are indicated by blue arrows. The red line marks the magnetic noon meridian

by white dashed circles, is identified at $\sim 1138 \mathrm{UT}$ at 7.5 MLT in both red and blue wavelengths, indicating that initially this is a PMAF in the dayside auroral oval. This PMAF shows a large azimuthal propagation in addition to poleward propagation and then evolves into a polar cap airglow patch, since there is no enhanced intensity inside the white dashed circle in subsequent blue emission snapshots in Fig. $1 \mathrm{Bg}-\mathrm{Bj}$. 

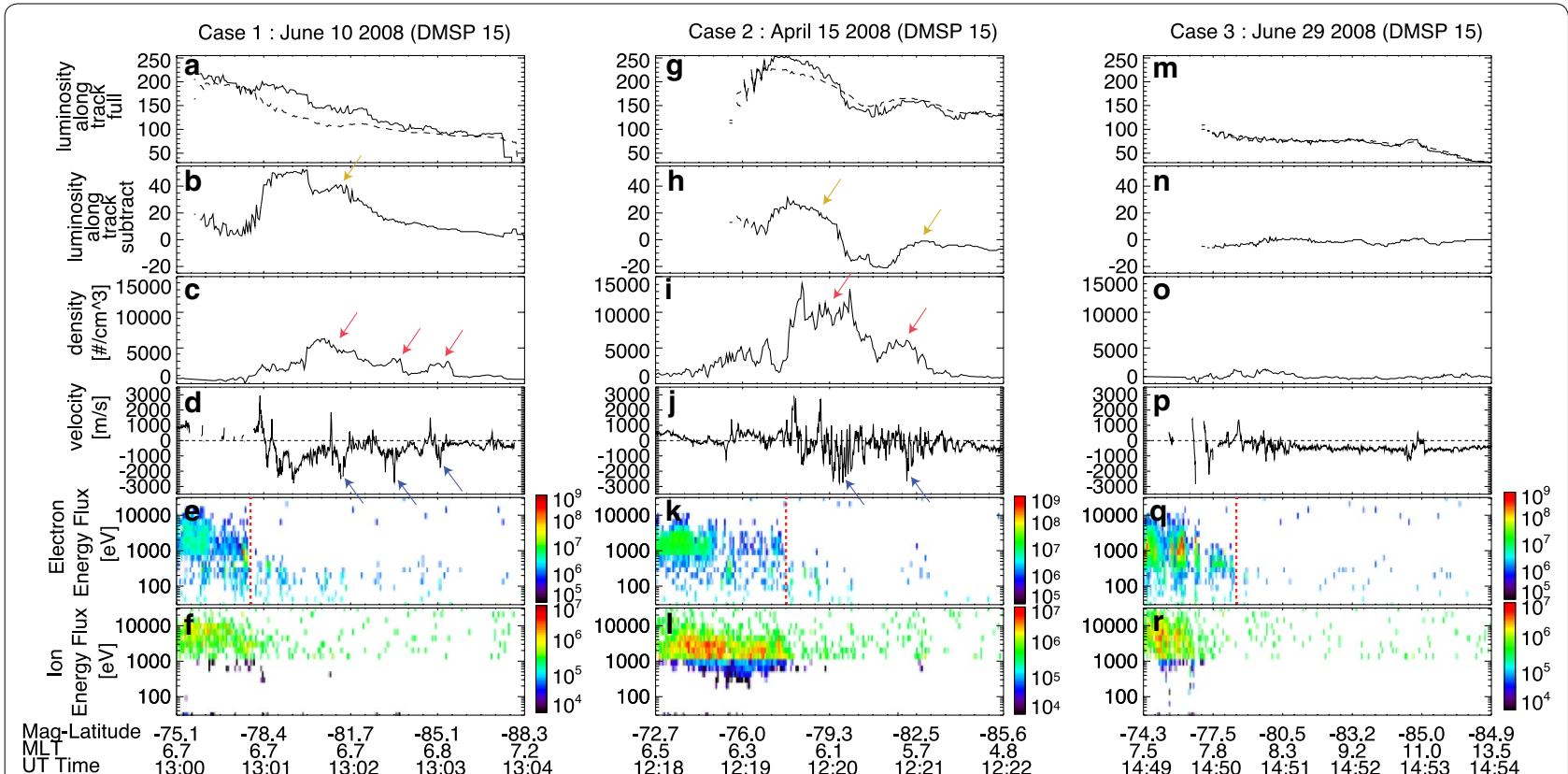

Fig. 2 Time series of $\mathbf{a}$ luminosity of ASI images along DMSP track, $\mathbf{b}$ luminosity of ASI images along DMSP track subtracting the background luminosity, $\mathbf{c}$ plasma density, $\mathbf{d}$ cross-track velocity, e electron energy flux and $\mathbf{f}$ ion energy flux by DMSP 15 for Fig. $1 \mathrm{Aa}-\mathrm{Aj}$ event. $\mathbf{g}-\mathbf{i}$ and $\mathbf{m}-\mathbf{r}$, which also show the data from DMSP 15, are given in the same format as a-f for Fig. 1Ba-Bj event and Fig. 1Ca-Cj events, respectively

Another PMAF is first identified in both red and blue emission snapshots (Fig. 1Bc, 1Bh, highlighted in green) at 8.2 MLT and $\sim 1205$ UT. Then this structure moved anti-sunward by $\sim 1$ MLT and then its $427.8 \mathrm{~nm}$ signature disappears (Fig. 1Bd, i), indicating the PMAF had evolved into an airglow patch. These events indicate that PMAFs can occur quite far away from noon and involve substantial azimuthal motion before connecting to polar cap patches.

DMSP 15 crossed these two airglow patches at $~ 1220$ UT (green dashed circle) and 1221 UT (white dashed circle). Much of the luminosity enhancements in Fig. $2 \mathrm{~h}$ are poleward of the electron precipitation boundary marked in panel $k$, confirming that these optical structures are polar cap airglow patches. The first enhancement of optical intensity at 1220 UT shown in Fig. $2 \mathrm{~g}$, h indicates the airglow patch that we identified in Fig. 1B by green dashed circles. Figure $2 \mathrm{i}$ shows the first density enhancement to be rough in association with this airglow patch. Within this significant enhancement of density, narrow anti-sunward flows (Fig. 2j) are identified. The maximum velocity of anti-sunward flow is $\sim 2800 \mathrm{~m} / \mathrm{s}$, which is much faster than the large-scale background velocity of $\sim 500 \mathrm{~m} / \mathrm{s}$ that can be seen toward the end of this time interval. There is also a fast sunward flow $(>1000 \mathrm{~m} / \mathrm{s})$ that is identified at 1219:55 UT near the anti-sunward flow. This indicates a large anti-sunward flow shear in this flow pattern although the sunward flow is much more localized than the anti-sunward flow.
The second enhancement of optical intensity at 1221 UT shown in Fig. $2 \mathrm{~g}$, $\mathrm{h}$ indicates the airglow patch that we identified in Fig. 1B by white dashed circles. DMSP 15 crosses this airglow patch at $\sim 5.8$ MLT, which is slightly out of our criterion for MLT of conjunction (6-18 MLT), and thus, this airglow patch is not included in our conjunction database, even though it evolved similarly to the first PMAF and patch, and was later measured by DMSP adjacent to the first airglow patch. The density of this airglow patch (Fig. 2i) reaches $\sim 6100 \# / \mathrm{cm}^{3}$, which is much larger than the background density after this density enhancement $\left(\sim 1000 \# / \mathrm{cm}^{3}\right)$. At the same time, a narrow anti-sunward flow with similar size to that of the airglow patch is identified. The maximum velocity of this flow is $\sim 2600 \mathrm{~m} / \mathrm{s}$, which is much faster than the background anti-sunward flow $(\sim 600 \mathrm{~m} / \mathrm{s}$ in this case). The satellite track is almost perpendicular to the patch propagation direction, and thus, the cross-track velocity detects the major component of the flow channel. This indicates that this flow channel structure is collocated with the airglow patch.

\section{Third case: June 29, 2008}

In previous two cases, dayside airglow patches are found to be associated with localized fast anti-sunward flows. To show that the fast flows are associated with the airglow patches, we here show a case during a quiet time without airglow patches (June 29, 2008). 
The $630.0-\mathrm{nm}$ emission is confined to $\sim-75^{\circ}$ to $80^{\circ}$ MLAT, and unlike in the previous two cases, no substantial $630.0-\mathrm{nm}$ emission is found poleward of the 427.8-nm emission, at least within the meridians where the 427.8-nm poleward boundary can be seen. DMSP 15 crossed the FOV of red emission images from 1451 UT to 1454 UT. During the conjunction period, the luminosity along the trajectory of DMSP 15 is much less than in the previous two cases (Fig. 2m). Correspondingly, Fig. 2o shows $\sim 1000 \# / \mathrm{cm}^{3}$ plasma density without significant enhancements. At the same time, the velocity of the antisunward flow pattern in this case is $\sim 600 \mathrm{~m} / \mathrm{s}$ throughout the conjunction period in the polar cap (except for shortlasting disturbances with a peak velocity of $\sim 1000 \mathrm{~m} / \mathrm{s}$ ). Such slower and wider flow is generally known as largescale two-cell convection, which is relatively steady and uniform during the quiet condition of polar cap.

\section{Statistical analysis}

We identified 50 conjunctions between polar cap airglow patches and DMSP satellites. In these cases, we compared the 427.8-nm poleward boundary and DMSP precipitation boundary. At least along the satellite trajectories, those boundaries agree with each other better than the $630.0 \mathrm{~nm}$ boundary. Based on those identified boundaries, PMAFs are observed to propagate inside the auroral oval and then evolve to airglow patches in the polar cap.

From the identified 50 conjunctions between airglow patches and DMSP satellites, mesoscale flow enhancements in the vicinity of airglow patches were found in 45 cases. The flow enhancements were defined as enhancements with a peak at least $500 \mathrm{~m} / \mathrm{s}$ larger than the flows in the surrounding region and a flow channel width less than $1000 \mathrm{~km}$, which is typical size of background polar cap convection pattern. We used these 45 cases to obtain statistical properties of polar cap airglow patches and related fast flows. The airglow patches for the 5 cases without localized fast flows were nearly stationary at the conjunction times, consistent with the lack of fast flows. It is possible that these few patches were carried into the polar cap by fast flows that dissipated prior to the satellite conjunction; however, this possibility cannot be tested with the present data set.

\section{Quantifying patch and flow channel properties}

To quantitatively characterize the 45 cases we found, we determined density and flow structures by calculating the maximum magnitude and widths around conjunction periods. Figure 3a, b illustrate how those calculations were performed. The vertical lines in Fig. 3a indicate the time period of the conjunction of the optical patch identified in Fig. 1Be. The density and velocity maxima within this time period are identified by the red dots. We only

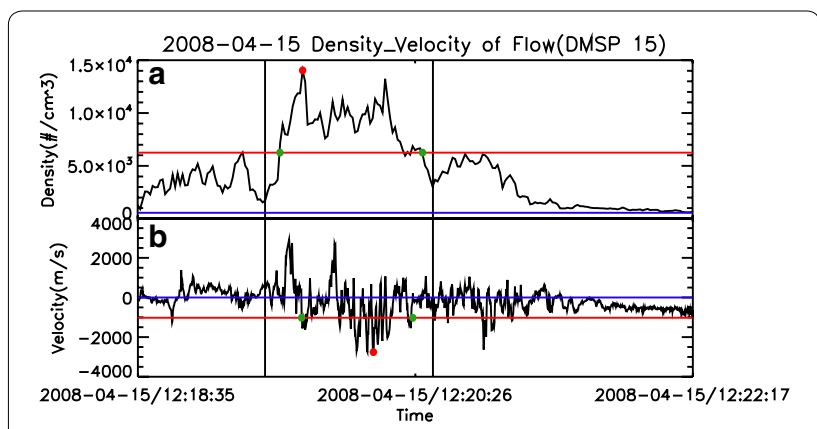

Fig. 3 Panels $\mathbf{a}, \mathbf{b}$ are blowups of Fig. $2 \mathrm{i}, \mathrm{j}$. The red and green points indicate the maximum density/velocity and the threshold values (see text) of density/velocity enhancements, respectively. The blue and red lines show background density/velocity and threshold values of density/velocity enhancements, respectively

consider the conjunction time periods to avoid including density enhancements associated with other patches that cannot be seen clearly in the images due possibly to their weaker airglow emissions and imager spatial resolution. The minimum density and anti-sunward velocity magnitude are identified during the interval from 2 min before to $2 \mathrm{~min}$ after the conjunction period. Those values are drawn as blue horizontal lines in Fig. 3a, b. We consider these minimum values as background density and velocity. The red lines mark $\left(A_{\max }-A_{\text {min }}\right) / e+A_{\text {min }}$, where $A$ denotes the density and velocity magnitude and $e$ is the Euler's number (see below the choice of this value). While the red lines cross the data points more than twice, we use the distance between the first and last crossing points during the conjunction period as in Fig. 3a and define this distance as the width of density. Similarly, we use the distance between the first and last points within the interval from 2 min before to 2 min after the conjunction period and define this distance as the width of the anti-sunward velocity enhancement. The 2 -min-longer window is used to ensure that flow enhancements wider than the density enhancements can be identified appropriately. If no flow channel exists, the width will be the size of the whole time window (a few thousand $\mathrm{km}$ )

Our choice of $e$ results from a trial of several different values. Our width definition somewhat differs from that by Coley and Heelis (1995), who identified density widths as two edges in which the plasma density is enhanced above $40 \%$ in $140 \mathrm{~km}$, and the overall enhancement is larger than $100 \%$ above the background. When a density enhancement only has a single peak, we checked that the edges obtained by our method and Coley and Heelis's method give essentially the same result. However, in cases where the enhanced density has multiple peaks, multiple sharp slopes meet their criteria, and hence, it becomes difficult to uniquely define density widths. Thus, 
our method can quantitatively find two edges that characterize density enhancements, and we confirmed the calculated widths by comparing to optical patch sizes from the AGO image data.

\section{IMF By and Bz dependence}

To find IMF conditions during our events, we took the median value of the OMNI 1-min resolution IMF data from 20 min before until the time of PMAF occurrence. Here, the 20-min threshold considers the timescale to change the large-scale current system in response to IMF variations (Anderson et al. 2014). This averaging removes short-lasting fluctuations and gives median IMF conditions that are expected to affect large-scale convection during our events. In this subsection, we removed 3 of the 45 cases because we cannot identify their corresponding PMAF within the FOV of images and another 2 cases without OMNI 1-min resolution IMF data, and thus, we investigated IMF dependence of airglow patches and related fast flows based on 40 cases. While most cases have steady IMF conditions during the 20-min IMF averaging period, three cases have IMF $\mathrm{Bz}$ sign changes of more than $\pm 1 \mathrm{nT}$ and thus these cases may involve large changes in background convection. Here, the threshold is based on the earlier study by Drury et al. (2003). These cases are marked in red when they appear in the panels of Fig. 4.

Figure $4 \mathrm{a}, \mathrm{b}$ shows the IMF By and Bz dependence of the MLT when patches depart from the poleward boundary of the auroral oval (hereinafter we call it depart-oval MLT). Here, we use |MLT-12| hours as the y-axis value of Fig. 4b, presenting the MLT separation between the patch departures from the poleward boundary of the auroral oval and magnetic noon. Plotted in black are the median and upper and lower quartiles every $1.4 \mathrm{nT}$. Here, the 1.4-nT number is obtained by splitting the $\mathrm{Bz}$ range into four segments, which gives more than three data points in each segment. Despite other limited number of events and the relatively large error bars, the figures give trends of the parameters shown.

Figure 4a shows the IMF By dependence of depart-oval MLT. Although the data points in Fig. 4a are scattered, the patches tend to depart to the polar cap on the dawnside when the IMF By is negative and on the duskside when the IMF By is positive. There is also evidence for a trend for patches to depart further toward the dawnside/duskside with increasing magnitude of IMF By. While the IMF By dependence is qualitatively consistent with the tilt of the two-cell convection pattern (e.g., Weimer 2005), the patches are often seen to exit before 9 MLT under large negative IMF By ( -5.0 nT). The patch departures can be found as early as $\sim 6$ MLT, which is much farther away from noon than previously studied by Drury et al. (2003), while the qualitative trend is consistent with their study. Since the throat of two-cell convection is not generally expected at such MLT, the patch motion likely involves substantial azimuthal propagation from initial PMAF locations closer to noon to the patch departure location.

The data points in Fig. 4b, which shows the IMF $\mathrm{Bz}$ dependence of depart-oval MLT, are much more scattered than those in Fig. 4a, and no depart-oval MLT dependence on IMF $\mathrm{Bz}$ is discernible.

\section{IMF clock angle dependence}

Figure 5a-d shows the IMF clock angle dependence of the maximum density, flow channel width and maximum flow speed associated with the polar cap patches. Clock
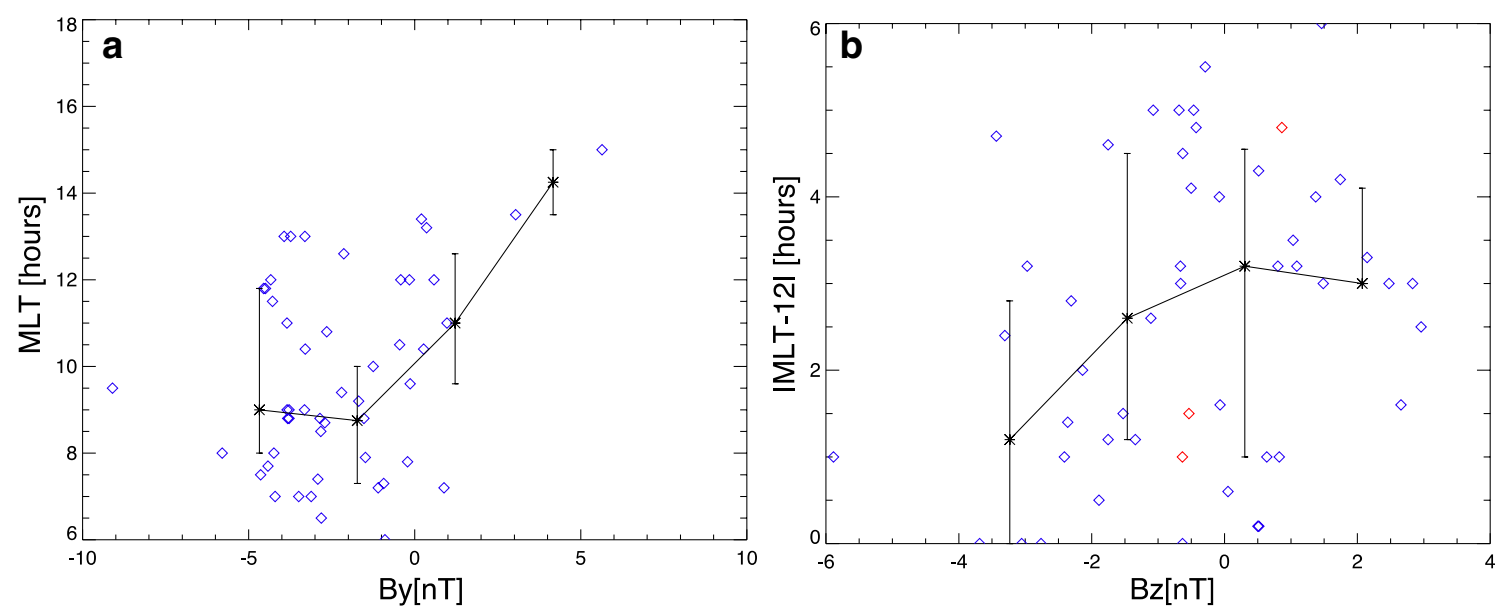

Fig. 4 IMF Bz and By dependence of depart-oval MLT is shown by $\mathbf{a}, \mathbf{b}$. The black stars and error bars indicate the medians and upper and lower quartiles every $1.4 \mathrm{nT}$. Blue and red diamonds represent cases with stable and fluctuating IMF Bz condition, respectively 
angle is the angle between GSM north and the projection of the IMF vector onto the GSM $\mathrm{y}-\mathrm{z}$ plane and is determined as the arctangent of By/Bz. In these figures, clock angles are from $0^{\circ}$ to $180^{\circ}$ clockwise from top to bottom. Figure $5 \mathrm{a}$ shows that most maximum densities of airglow patches are relatively small for small ratio of IMF $|\mathrm{Bz}|$ and $|\mathrm{By}|$. Although the flow channel widths shown in Fig. 5c do not show a clear trend, since all measured widths are less than $1000 \mathrm{~km}(\sim 300 \mathrm{~km}$ on average), these are all localized flow channels rather than larger-scale convection, which would extend over a few $1000 \mathrm{~km}$. Interestingly, a notable IMF By effect is shown in Fig. 5d, where fast flows of $>\sim 1500 \mathrm{~m} / \mathrm{s}$ are predominantly seen during large $|\mathrm{By}|$ and small $|\mathrm{Bz}|$. Under a large IMF By condition, it has been observed that mesoscale flows in the cusp region propagate poleward, and this has been suggested to be due to large tension force in dayside reconnection under large IMF $|\mathrm{By}|$ (Sandholt et al. 2004; Lockwood et al. 2005; Rinne et al. 2010; Zhang et al. 2011, 2013b). Combining with our observation, these mesoscale flows may move far away from the noon meridian and then propagate into the polar cap. The bias toward negative By is due to the conjunctions (DMSP within ASI FOV) occurring preferentially at pre-noon MLT. The average flow speed is $\sim 1100 \mathrm{~m} / \mathrm{s}$.

\section{Conclusion}

To understand the propagation relations between, and characteristics of, dayside polar cap patches and related flow structures, we traced airglow patches and

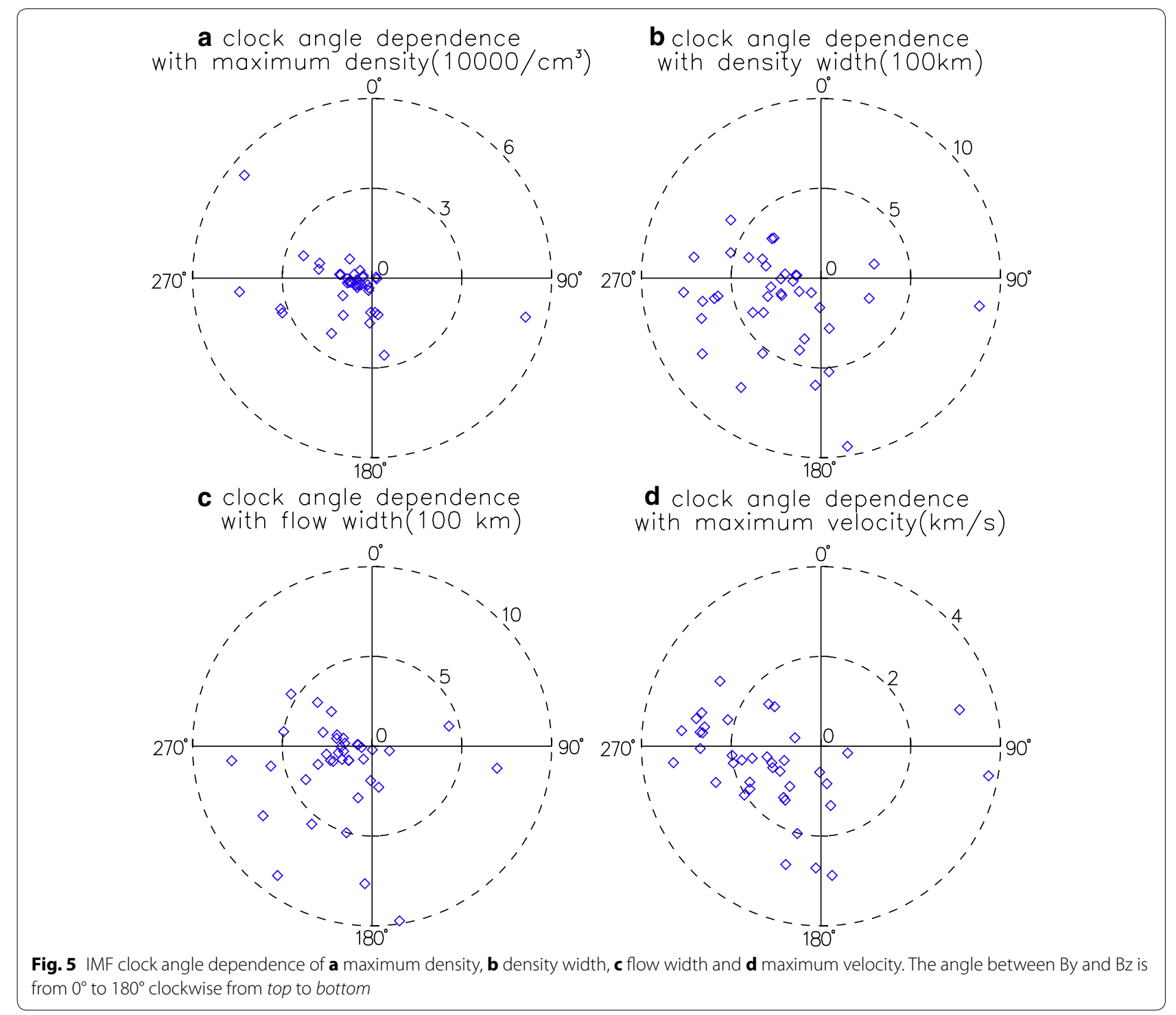


investigated density and flow structures under different IMF conditions using coordinated observations of the AGO ASI and DMSP satellites in the southern hemisphere.

We showed that polar cap patches are often (45 out of 60 events) collocated with longitudinally narrow flow enhancements. Flow velocities over the patches are substantially larger than in the surrounding regions that would represent large-scale background convection, and the flow channel widths are comparable to the enhanced density widths. We thus conclude that dayside polar cap patches are associated with localized polar cap flow enhancements rather than patches being carried by large-scale convection. Since the patches emanated from PMAFs within the dayside auroral oval, we suggest that the flow channels may originate in the dayside auroral oval and propagate into the polar cap. Dayside reconnection could be a trigger of the fast flows that bring enhanced density from the dayside auroral oval to the polar cap by maintaining the flow channel characteristics over substantial distances. Furthermore, the dayside flow channels could be the source of those measured in the nightside polar cap.

We also found that many PMAFs move azimuthally away from noon over a few hours of MLT and then leave polar cap patches behind just poleward of the auroral oval. The departure into the polar cap can be found as early as 6 MLT. These patches away from noon tend to be measured when the IMF By is large. Thus, we also investigated the IMF clock angle dependence of properties of the airglow patches and related fast flows. The flow channel speeds average $1100 \mathrm{~m} / \mathrm{s}$ over the observed patches, and the average width is $300 \mathrm{~km}$. More broad density enhancements and flow channels $(>\sim 500 \mathrm{~km})$ occur during southward Bz. It is also interesting that large enhancement of density $\left(>\sim 30,000 \# / \mathrm{cm}^{3}\right)$ are By dominated. Fast flows of $>\sim 1500 \mathrm{~m} / \mathrm{s}$ are predominantly seen during large IMF - By and small $|\mathrm{Bz}|$, consistent with enhanced thermospheric cusp heating with increasing $|\mathrm{By}|$ (Carlson 2012), and the flow speed decreases with increasing - Bz.

The -By preference is consistent with the duskside convection cell extending toward dawn and giving a higher possibility of a flow channels being seen on the dawnside FOV. It is known that for large, negative By, the boundary between dawn and dusk convection cells is shifted toward dawn in the southern hemisphere (Reiff and Burch 1985; Lyons et al. 1996) and toward dusk in the northern hemisphere (Weimer 2005). Additionally, the previous case studies have shown the IMF By-related formation of polar cap patches (Lockwood et al. 2005; Zhang et al. 2011, 2013b). In our study, we statistically showed that the departing points of these patches from the poleward boundary of auroral oval are associated with IMF By, and moreover, the airglow patches that depart at $<9$ MLT are with strong negative By. Thus, our observations suggest that patches and flow channels with high flow speeds are guided by the asymmetric By flow pattern, bringing them toward dawn in the southern hemisphere.

\section{Additional file}

Additional file 1. The list of all the conjunction events in our database through 2007 to 2011. "Conjunction Time" column shows the time of conjunction between ASI image and DMSP satellite; "PMAF time" shows the time of the first appearance of the corresponding PMAF that evolved to the airglow patch; "DMSP" column shows the satellite number; "Conj_MLT" shows the MLT at the conjunction time; "Conj_MLAT" shows the Magnetic latitude at the conjunction time; "Dep_MLT" shows the MLT when the airglow patch exits the poleward boundary of the dayside auroral oval; "Width of density" column shows the width of the density enhancement; "Maximum density" column shows maximum density of the density enhancement; "Width of velocity" column shows the width of the velocity enhancement; "Maximum velocity" column shows the maximum of the velocity magnitude; "By" column shows average IMF By between -20 min and PMAF time and "-" means no IMF data or no identified PMAF time; "Bz" column shows average IMF Bz between -20 min and PMAF time and "-" means no IMF data or no identified PMAF time. The grey rows present the cases without localized anti-sunward fast flow.

\section{Authors' contributions}

BY conducted all data analyses and wrote the paper under guidance by YN and LRL. YZ assisted data processing. HCC helped interpretation of results. HUF and SBM provided imager data and comments for data analysis. All authors read and approved the final manuscript.

\section{Author details}

${ }^{1}$ Department of Atmospheric and Oceanic Sciences, University of California, Los Angeles, Los Angeles, CA, USA. ${ }^{2}$ Space Weather Center, CASS, Utah State University, Logan, UT, USA. ${ }^{3}$ Space Sciences Laboratory, University of California, Berkeley, Berkeley, CA, USA.

\section{Acknowledgements}

This work was supported by NASA Grants NNX15Al62G, NSF Grants PLR1341359, AGS-1451911, AGS-1451911, OGFR 09-09-004 and AGS-1011921. The DMSP data are maintained by the Air Force Research Laboratory and Applied Physics Laboratory at Johns Hopkins University. The OMNI solar wind data were obtained from the CDAWeb. The imager and satellite data can be provided from the authors upon request.

Competing interests

The authors declare that they have no competing interests.

Received: 1 December 2015 Accepted: 18 August 2016

Published online: 02 September 2016

\footnotetext{
References

Anderson BJ, Korth H, Waters CL, Green DL, Merkin VG, Barnes RJ, Dyrud LP (2014) Development of large-scale Birkeland currents determined from the active magnetosphere and planetary electrodynamics response experiment. Geophys Res Lett. doi:10.1002/2014GL059941

Axelsson K, Sergienko T, Nilsson H, Brändström U, Asamura K, Sakanoi T (2014) First negative system of $\mathrm{N}^{2+}$ in aurora: simultaneous space-borne and ground-based measurements and modeling results. Ann Geophys 32:499-506. doi:10.5194/angeo-32-499-2014

Carlson HC (2012) Sharpening our thinking about polar cap ionospheric patch morphology, research, and mitigation techniques. Radio Sci. doi:10.1029 /2011rs004946
} 
Carlson HC, Oksavik K, Moen J, Pedersen T (2004) Ionospheric patch formation: direct measurements of the origin of a polar cap patch. Geophys Res Lett 31(8):L08806. doi:10.1029/2003GL018166

Carlson HC, Moen J, Oksavik K, Nielsen CP, McCrea IW, Pedersen TR, Gallop P (2006) Direct observations of injection events of subauroral plasma into the polar cap. Geophys Res Lett. doi:10.1029/2005GL025230

Coley WR, Heelis RA (1995) Adaptive identification and characterization of polar ionization patches. J Geophys Res 100(A12):23819-23827. doi:10.1029/95JA02700

Drury EE, Mende SB, Frey HU, Doolittle JH (2003) Southern Hemisphere poleward moving auroral forms. J Geophys Res. doi:10.1029/2001JA007536

Foster JC (1984) lonospheric signatures of magnetospheric convection. J Geophys Res Space Phys 89(A2):855-865. doi:10.1029/JA089iA02p00855

Foster JC, Coster AJ, Erickson PJ, Holt JM, Lind FD, Rideout W, McCready M, Van Eyken A, Barnes RJ, Greenwald RA, Rich FJ (2005) Multiradar observations of the polar tonque of ionization. J Geophys Res 110:A09S31. doi:10.1029 /2004JA010928

Goodwin L, Iserhienrhien B, Miles DM, Patra S, van der Meeren C, Buchert SC, Burchill J, Clausen LBN, Knudsen DJ, McWilliams KA, Moen JI (2015) Swarm in situ observations of F-region polar cap patches created by cusp precipitation. Geophys Res Lett. doi:10.1002/2014GL062610.

Hosokawa K, Kashimoto T, Suzuki S, Shiokawa K, Otsuka Y, Ogawa T (2009) Motion of polar cap patches: a statistical study with all-sky airglow imager at Resolute Bay, Canada. J Geophys Res 114:A04318. doi:10.1029/2008JA014020

Hosokawa K, St-Maurice J-P, Sofko GJ, Shiokawa K, Otsuka Y, Ogawa T (2010) Reorganization of polar cap patches through shears in the background plasma convection. J Geophys Res. doi:10.1029/2009JA014599

Knudsen WC (1974) Magnetospheric convection and the high-latitude $F_{2}$ ionosphere. J Geophys Res 79(7):1046-1055. doi:10.1029/JA079i007p01046

Lockwood M, Milan SE, Onsager T, Perry CH, Scudder JA, Russell CT, Brittnacher M (2001) Cusp ion steps, field-aligned currents and poleward moving auroral forms. J Geophys Res 106(A12):29555-29569. doi:10.1029/200 OJA900175

Lockwood M, Davies JA, Moen J, van Eyken AP, Oksavik K, McCrea IW, Lester M (2005) Motion of the dayside polar cap boundary during substorm cycles: II. Generation of poleward-moving events and polar cap patches by pulses in the magnetopause reconnection rate. Ann Geophys 23(11):3513-3532. doi:10.5194/angeo-23-3513-2005

Lorentzen DA, Shumilov N, Moen J (2004) Drifting airglow patches in relation to tail reconnection. Geophys Res Lett. doi:10.1029/2003GL017785

Lorentzen DA, Moen J, Oksavik K, Sigernes F, Saito Y, Johnsen MG (2010) In situ measurement of a newly created polar cap patch. J Geophys Res. doi:10 1029/2010JA015710

Lyons LR, Lu G, dela Beaujardiere O, Rich FJ (1996) Synoptic maps of polar caps for stable interplanetary magnetic field intervals during January 1992 geospace environment modeling Campaign. J Geophys Res 101(A12):27283-27298. doi:10.1029/96ja02457

Lyons LR, Nishimura Y, Kim H-J, Donovan E, Angelopoulos V, Sofko G, Nicolls M, Heinselman C, Ruohoniemi JM, Nishitani N (2011) Possible connection of polar cap flows to pre- and post-substorm onset PBIs and streamers. J Geophys Res. doi:10.1029/2011JA016850

MacDougall JW, Jayachandran PT (2001) Polar cap convection relationships with solar wind. Radio Sci 36(6):1869-1880. doi:10.1029/2001RS001007

McWilliams KA, Yeoman TK, Cowley SWH (2000) Two-dimensional electric field measurements in the ionospheric footprint of a flux transfer event. Ann Geophys 18:1584-1598. doi:10.1007/s00585-001-1584-2

Mende SB, Frey HU, Geller SP, Doolittle JH (1999) Multistation observations of auroras: polar cap substorms. J Geophys Res 104(A2):2333-2342. doi:10.1 029/1998JA900084

Milan SE, Lester M, Cowley SWH, Brittnacher M (2000) Convection and auroral response to a southward turning of the IMF: polar UVI, CUTLASS, and IMAGE signatures of transient magnetic flux transfer at the magnetopause. J Geophys Res 105(A7):15741-15755. doi:10.1029/2000JA900022

Moen J, Sandholt PE, Lockwood M, Denig WF, Løvhaug UP, Lybekk B, Egeland A, Opsvik D, Friis-Christensen E (1995) Events of enhanced convection and related dayside auroral activity. J Geophys Res Space Phys 100(A2):23917-23934. doi:10.1029/95JA02585

Moen J, Gulbrandsen N, Lorentzen DA, Carlson HC (2007) On the MLT distribution of $\mathrm{F}$ region polar cap patches at night. Geophys Res Lett. doi:10.102 9/2007GL029632
Moen J, Qiu XC, Carlson HC, Fujii R, McCrea IW (2008a) On the diurnal variability in $\mathrm{F}_{2}$-region plasma density above the EISCAT Svalbard radar. Ann Geophys 26(8):2427-2433. doi:10.5194/angeo-26-2427-2008

Moen J, Rinne Y, Carlson HC, Oksavik K, Fujii R, Opgenoorth H (2008b) On the relationship between thin Birkeland current arcs and reversed flow channels in the winter cusp/cleft ionosphere. J Geophys Res. doi:10.1029/200 8JA013061

Moen J, Hosokawa K, Gulbrandsen N, Clausen LBN (2015) On the symmetry of ionospheric polar cap patch exits around magnetic midnight. J Geophys Res Space Phys. doi:10.1002/2014JA020914

Nishimura Y, Lyons LR, Zou S, Angelopoulos V, Mende SB (2010) Reply to comment by Harald U. Frey on "Substorm triggering by new plasma instrusion: THEMIS all-sky imager observations". J Geophys Res. doi:10.10 29/2010JA016182

Nishimura Y, Lyons LR, Shiokawa K, Angelopoulos V, Donovan EF, Mende SB (2013) Substorm onset and expansion phase intensification precursors seen in polar cap patches and arcs. J Geophys Res 118(5):2034-2042. doi:10.1002/jgra.50279

Nishimura Y et al (2014) Day-night coupling by a localized flow channel visualized by polar cap patch propagation. Geophys Res Lett 41(11):3701-3709. doi:10.1002/2014GL060301

Oksavik K, Moen J, Carlson HC (2004) High-resolution observations of the small-scale flow pattern associated with a poleward moving auroral form in the cusp. Geophys Res Lett. doi:10.1029/2004GL019838

Oksavik K, Moen J, Carlson HC, Greenwald RA, Milan SE, Lester M, Denig WF, Barnes RJ (2005) Multi-instrument mapping of the small-scale flow dynamics related to a cusp auroral transient. Ann Geophys 23(7):26572670. doi:10.5194/angeo-23-2657-2005

Oksavik K, Barth VL, Moen J, Lester M (2010) On the entry and transit of highdensity plasma across the polar cap. J Geophys Res. doi:10.1029/201 OJA015817

Pinnock M, Rodger AS, Dudeney JR, Baker KB, Newell PT, Greenwald RA, Greenspan ME (1993) Observations of an enhanced convection channel in the cusp ionosphere. J Geophys Res 98(A3):3767-3776. doi:10.1029/92JA01382

Provan G, Yoeman TK (1999) Statistical observations of the MLT, latitude and size of pulsed ionospheric flows with the CUTLASS Finland radar. Ann Geophys 17(7):855-867. doi:10.1007/s00585-999-0855-1

Provan G, Yoeman TK, Milan SE (1998) CUTLASS Finland radar observations of the ionospheric signatures of flux transfer events and the resulting plasma flows. Ann Geophys 16(11):1411-1422. doi:10.1007/ s00585-998-1411-0

Provan G, Yoeman TK, Cowley SWH (1999) The influence of the IMF By component on the location of pulsed flows in the dayside ionosphere observed by an HF radar. Geophys Res Lett 26(4):521-524. doi:10.1029/1 999GL 900009

Reiff PH, Burch JL (1985) IMF By-dependent plasma flow and Birkeland currents in the dayside magnetosphere: 2. A global model for northward and southward IMF. J Geophys Res 90(A2):1595-1609. doi:10.1029/ JA090iA02p01595

Rinne Y, Moen J, Oksavik K, Carlson HC (2007) Reversed flow events in the winter cusp ionosphere observed by the European Incoherent Scatter (EISCAT) Svalbard radar. J Geophys Res. doi:10.1029/2007JA012366

Rinne Y, Moen J, Carlson HC, Hairston MR (2010) Stratification of east-west plasma flow channels observed in the ionospheric cusp in response to IMF By polarity changes. Geophys Res Lett. doi:10.1029/2010GL043307

Sakai J, Hosokawa K, Taguchi S, Ogawa Y (2014) Storm time enhancements of $630.0 \mathrm{~nm}$ airglow associated with polar cap patches. J Geophys Res Space Phys 119:2214-2228. doi:10.1002/2013JA019197

Sandholt PE, Farrugia CJ (2003) Does the aurora provide evidence for the occurrence of antiparallel magnetopause reconnection? I Geophys Res. doi:10.1029/2003JA010066

Sandholt PE, Farrugia CJ, Denig WF (2004) Dayside aurora and the role of IMF $|\mathrm{By}| /|\mathrm{Bz}|$ : detailed morphology and response to magnetopause reconnection. Ann Geophys 22(2):613-628. doi:10.5194/angeo-22-613-2004

Weber EJ, Buchau J (1981) Polar cap F-layer auroras. Geophys Res Lett 8(1):125-129. doi:10.1029/GL008i001 p00125

Weimer DR (2005) Improved ionospheric electrodynamic models and application to calculating Joule heating rates. J Geophys Res. doi:10.1029/200 4JA010884 
Wilder FD, Crowley G, Eriksson S, Newell PT, Hairston MR (2012) lonospheric Joule heating, fast flow channels, and magnetic field line topology for IMF By-dominant conditions: observations and comparisons with predicted reconnection jet speeds. J Geophys Res 117:A11311. doi:10.10 29/2012JA017914

Zhang Q-H, Zhang B-C, Liu R-Y, Dunlop MW, Lockwood M, Moen J, Yang H-G, Hu H-Q, Hu Z-J, Liu S-L, McCrea IW, Lester M (2011) On the importance of IMF |By| on polar cap patch formation. J Geophys Res 116:A05308. doi:10. 1029/2010JA016287

Zhang Q-H, Zhang B-C, Lockwood M, Hu H-Q, Moen Jl, Ruohoniemi JM, Thomas EG, Zhang S-R, Yang H-G, Liu R-Y, McWilliams K, Baker JBH (2013a) Direct observations of the evolution of polar cap ionization patches. Science 339(6127):1597-1600. doi:10.1126/science.1231487
Zhang Q-H, Zhang B-C, Moen JI, Lockwood M, McCrea IW, Yang H-G, Hu H, Liu R-Y, Zhang S-R, Lester M (2013b) Polar cap patch segmentation of the tongue of ionization in the morning convection cell. Geophys Res Lett 40(12):s2918-s2922. doi:10.1002/grl.50616. ISSN 0094-8276

Zou Y, Nishimura Y, Lyons LR, Donovan EF, Ruohoniemi JM, Nishitani N, McWilliams KA (2014) Statistical relationships between enhanced polar cap flows and PBls. J Geophys Res 119(1):151-162. doi:10.1002/2013JA019269

\section{Submit your manuscript to a SpringerOpen ${ }^{\circ}$ journal and benefit from:}

- Convenient online submission

- Rigorous peer review

- Immediate publication on acceptance

- Open access: articles freely available online

- High visibility within the field

- Retaining the copyright to your article 